\title{
FINANCIAMIENTO DE INVERSIONES ESTRATÉGICAS Y EL MERCADO DE CAPITALES EN EL PERÚ
}

\section{STRATEGIC INVESTMENT FINANCING AND CAPITAL MARKETS IN PERU}

\author{
Raúl Arrarte Mera* \\ Docente Asociado de la Facultad de Ciencias Contables - UNMSM
}

[Recepción: Febrero de 2011/ Conformidad: Abril de 2011]

\section{RESUMEN}

Una de las críticas fundamentales al modelo económico peruano, aplicado por el Gobierno de turno, es que mediante la apertura irrestricta del mercado nacional a la inversión extranjera puede lograrse un crecimiento económico sostenido. Esto se plasma en el Art. 63 de la Constitución de 1993, que dice: "la inversión nacional y la extranjera se sujetan a las mismas condiciones" ${ }^{\text {. Así la }}$ inversión extranjera puede entrar a cualquier sector económico, desde el petróleo, la minería, la petroquímica, las líneas aéreas, los puertos, el sector financiero, las telecomunicaciones, etc. En esta visión, no existen sectores ni empresas estratégicas, por tanto, el Estado debe sustraerse de cualquier injerencia o tentativa de regulación ${ }^{2}$.

El objetivo de esta investigación es presentar propuestas para reservar los sectores estratégicos con presencia obligada del capital nacional con financiamiento en la Bolsa de Valores de Lima; y aprovechar la oportunidad para desarrollar el mercado de capitales, buscando la transparencia en la información financiera, como sociedades anónimas abiertas, y evitar a futuro casos como de Doe Run Perú, establecida como Sociedad Mercantil de Responsabilidad Limitada.

La metodología del trabajo es Descriptivo, porque pretende analizar, evaluar y explicar

\begin{abstract}
One of the fundamental criticisms of the Peruvian economic model, implemented by the government of the day, is that through the unrestricted opening of the domestic market to foreign investment can be achieved sustained economic growth. This is reflected in Article 63 of the 1993 Constitution, which reads: "The domestic and foreign investments are subject to the same conditions. So the foreign investors can enter any economic sector, from oil, mining, petrochemicals, airlines, ports, financial sector, telecommunications, etc. In this view, there are strategic sectors or enterprises; therefore, the State should be excluded from any interference or attempt to control.

The objective of this research is to present proposals to reserve to-face strategic sectors of national capital funding in the Lima Stock Exchange, and take the opportunity to develop the capital market, looking for transparency in financial reporting, as companies open corporations, and avoid future cases such as Doe Run Peru, established as a Limited Liability Company Commercial.

The methodology of this study is a descriptive, because it seeks to analyze, evaluate and explain the effects of current funding model for private investment by the indiscriminate
\end{abstract}

* Contador Público Colegiado, Maestro en Administración y Doctor en Ciencias Contables y Empresariales. Actual Director del Instituto de Investigaciones en Ciencias Financieras y Contables. E-mail: raularrarte@speedy.com.pe

1 Humberto Campodónico. "TLC Perú-Chile: No Hay Igualdad de Trato". Diario "La República” 11.03.09. Lima. Perú .

2 Humberto Campodònico. Artìculo anterior ya citado. 
los efectos del modelo actual de financiamiento de las inversiones privadas por la apertura indiscriminada del mercado nacional a la inversión extranjera directa.

Se hizo recolección de información documental del Ministerio de Economía y Finanzas (MEF), Banco Central de Reserva del Perú, (BCRP), Comisión Nacional Supervisora de Empresas y Valores (CONASEV), y demás analistas nacionales y extranjeros expertos en temas del mercado de capitales.

Los resultados de este trabajo fueron difundidos en el Taller de Investigación 2010 de la Facultad de Ciencias Contables de la UNMSM; y sus conclusiones serán entregadas al Congreso Nacional de la República, CONASEV, y Bolsa de Valores de Lima (BVL).

El tamaño de la muestra está representada por las inversiones que desarrolla la Agencia de Promociòn de la Inversión Privada (PROINVERSIÓN).

La conclusión principal es modificar el Artículo 60, tercer párrafo, de nuestra Constitución Política vigente en los siguientes términos: "La actividad empresarial, pública o no pública, recibe el mismo tratamiento legal. Pero las inversiones en los sectores: Agua y Saneamiento; Energía Eléctrica e Hidroeléctrica; Gas; Hidrocarburos; Investigación y Desarrollo; Puertos y Aeropuertos, se constituirán como Sociedades Anònimas Abiertas y tendrán la obligación de colocar un $20 \%$ mìnimo de su capital social en la Bolsa de Valores de Lima”.

Palabras Clave: Financiamiento de Inversiones, Inversiones Estratégicas, Inversión Estratégica Directa. Mercado de Capitales. opening of the domestic market to foreign direct investment.

Collection was made documentary information from the Ministry of Economy and Finance (MEF), Central Bank of Peru (BCRP), National Supervisory Commission for Companies and Securities (CONASEV), analysts and other national and foreign experts in market capital. The results of this study will be reported in the 2010 Research Workshop of the School of Accounting of San Marcos, to be published an article in the Journal of Research "Quipukamayoc" of the Faculty and its findings submitted to the National Congress of the Republic, CONASEV, and Lima Stock Exchange (BVL).

The objective of this research is to present proposals to amend the Constitution of Peru in the sense of maintaining a presence in strategic sectors of the national capital required to finance the Lima Stock Exchange, and take the opportunity to develop the capital market looking for transparency in financial reporting, as open corporations, and avoid future cases such as Doe Run Peru, established as a Limited Liability Company Commercial. Participating units are: the Ministry of Economy and Finance, Agency for Promotion of Private Investment (PROINVERSIÓN), the National Supervisory Commission for Companies and Securities (CONASEV), the Lima Stock Exchange.

The results of this study were reported in the 2010 Research Workshop of the School of Accounting of San Marcos, and its findings submitted to the CONASEV STOCK EXCHANGE LIMA and PROINVERSIÓN.

The main conclusion is to amend Article 60, third paragraph, of our current Constitution as follows: "Business, public or nonpublic, receives the same legal treatment. But investments in the sectors: Water and Sanitation and Hydroelectric Power, Gas, Oil, Research and Development, Ports and Airports, will be formed as open corporations and are obliged to put at least $20 \%$ of its share capital in Lima Stock Exchange”.

The sample size is represented by investments that promote Promotion Agency of Private Investment (PROINVERSIÓN).

Keywords: Investment Financing, Strategic Investments, Strategic Direct Investment. Capital Markets. 
CAPÍTULO I. DIAGNÓSTICO SOBRE EL FINANCIAMIENTO ACTUAL EN MERCADO DE CAPITALES DEL PERÚ

A. PANORAMA DE la bOLSA DE VA-

\section{LORES DE LIMA}

El problema fundamental de la clase empresarial peruana es su debilidad patrimonial y debemos procurar que las empresas aumenten su estructura de financiamiento con capital propio para que sean sólidas y no tengan un alto palanqueo financiero que las ha puesto débiles y ha determinado que entre 1995-2000 existan 3,955 empresas en proceso de reestructuración.

En comparación con otros países, el mercado de capitales del Perú se encuentra en una etapa incipiente ${ }^{3}$. Los bancos siguen siendo la fuente principal de financiamiento de las empresas peruanas (el 69\% de los créditos a empresas peruanas provienen de los bancos), pero en el contexto de un desarrollo económico favorable y con exportaciones crecientes, la evolución del mercado de capitales tiene buenas expectativas.

Se caracteriza por tener pocos inversionistas y pocas empresas que emiten acciones. Por ejemplo, existen 5 fondos privados de pensiones que compran aproximadamente el $33 \%$ de todas las acciones emitidas, y 2 empresas aseguradoras su mercado -formado por 5 empresas- con más de $60 \%$. Asimismo, unas 12 grandes instituciones representan el 90\% de todas las emisiones bursátiles, entre ellas los bancos más importantes y diversas empresas como Gloria, Luz del Sur, Telefónica, Edegel, Edelnor, Supermercados y una Universidad local. Otra característica impor- tante del mercado de capitales es la dolarización, que llega a más de $60 \%$ pero que está en desarrollo hacia la baja gracias a las mayores emisiones en moneda local.

\section{Buscando eficiencia en la actividad empresarial del estado.}

En este panorama, el Ministerio de Economía y Finanzas $(\mathrm{MEF})^{4}$ publicó el Reglamento de la Ley 1031, que promueve la eficiencia de la actividad empresarial del Estado, que entre otros aspectos, permite la participación del capital privado en las empresas del Estado a través de la venta de acciones. La norma aprobada por Decreto Supremo No. 176-2010.EF, dispone en su artículo 36 que las empresas del Estado podrán recibir nuevos aportes de capital de inversionistas privados, los mismos que se sustentarán en las disposiciones y garantías de la Ley General de Sociedades. Reglamento que ha sido consultado a la CONASEV y a la Superintendencia de Banca y Seguros. $Y$ las primeras en listar podrían ser las Empresas Eléctricas que están más preparadas y ya listan en la Bolsa de Valores ${ }^{5}$. El Estado es propietario de 16 empresas de generación y distribución eléctrica.

Los mecanismos a considerarse para esta participación privada son: la transferencia del total o de una parte de las acciones o activos; el aumento de capital; la celebración de contratos de asociación, "joint ventures", asociación en participación, prestación de servicios, arrendamientos, gerencia, concesión u otros similares y la disposición o venta de sus activos, cuando ella se haga con moti-

3 Delegaciòn de la Comisiòn Europea en el Perù.

4 Sonia Gilvonio M. "Se abre el camino para la venta de acciones de las empresas públicas". Diario "Gestión". 31.08.2010. Pàgina 4. Lima. Perù.

5 En Junio del 2010, el FONAFE informó que alistaba los Estados Financieros de Electro Ucayali, Activos Mineros, Editora Perú, Enapu, Sima y Corpac, para listarlos en la Bolsa de Valores de Lima. 
vo de su disolución y liquidación. Tal como lo dispone el Decreto Legislativo 674.

\section{Promoviendo accionariado difundido en empresas estatales}

El 27 de Abril último, (2010), la CONASEV inscribió las acciones comunes clase B de Petroperú en el Registro Público del Mercado de Valores y su listado en la Bolsa de Valores de Lima. El Ministerio de Economía y Finanzas anunció que se vendería, en principio, hasta un $\mathbf{2 0 \%}$.

La opinión de economistas peruanos que han estudiado el tema del Mercado de Capitales se resume en los siguientes comentarios: Aunque está recobrando importancia como fuente de financiamiento, nuestro mercado aún está lejos de los niveles alcanzados en la década pasada y sigue siendo pequeñísimo en comparación con las otras economías de la región. Los máximos niveles de volumen negociado tanto en renta variable como en renta fija se alcanzaron en 1997 (10.3\% y $10.2 \%$ del PBI, respectivamente), mientras que en el 2004 estos fueron de 2.3\% del PBI en renta variable y $1.3 \%$ del PBI en renta fija. En Chile, los montos negociados por renta variable y fija en el 2004 alcanzaron el 12.8\% y $121.6 \%$ del PBI, respectivamente (el total negociado alcanzó el $268 \%$ del PBI) 6 .

En el fondo la economía peruana ha entrado en un nuevo modelo de acumulación de capital, cuyas características principales están en éstos aspectos:

1. La mayor participación del financiamiento (ahorro) externo en la inversión productiva centrada en los sectores extractivos (minería, gas) y de servicios (comercio, hoteles, bancos).
2. La configuración de un dualismo tecnológico debido a que las inversiones de mayor escala tienen tecnologías indivisibles o inaccesibles para los pequeños y medianos inversionistas, además la tecnología es mayormente importada en consecuencia no genera una demanda efectiva interna por bienes de capital o de procesos tecnológicos. Un efecto importante de este dualismo tecnológico es la baja generación de empleo decente de las acciones de Petroperú 7 .

\section{Debilidades de la bolsa de valores de lima (BVL)}

Este equipo de Investigadores identifica las siguientes debilidades:

- Pequeño, poco profundo, concentrado y poco dinámico

- Exceso de demanda sobre oferta

- Poca liquidez en mercado secundario (renta fija)

- Pocas nuevas emisiones de acciones en últimos años

- Proceso de aprobaciones ha mejorado pero todavía se percibe lento

- Altos costos de emisión para empresas medianas

- Percepción de que malas prácticas no se fiscalizan o sancionan.

Sin embargo, consideran insuficientes las propuestas planteadas por las autoridades fiscales, para reformar el mercado de capitales, por lo siguiente:

- La propuesta oficial nos parece positiva.

- Una reforma implica mucho más que lo enunciado.

- Se requiere mayor ambición (y especificidad).

\footnotetext{
6 Instituto Peruano de Economía. "El Mercado de Capitales Peruanos: Propuesta para Desarrollarlo. (2005).
}

7 Efraín Gonzales de Olarte.“Economía Política de la Reforma del Estado en el Perú”. 17.04.206. 
- Habría sido útil que se coordine con sector privado previo al anuncio ${ }^{8}$.

El gurú mundial sobre estrategia y competitividad, Michael Porter, reconoció que el Perú ha crecido mucho en los últimos años, pero ese crecimiento no se ha reflejado en beneficio de la mayoría de la población. En una exposición presentando al "Seminario Internacional: Claves de una Estrategia Competitiva”, organizado por la Universidad del Pacífico, opinó que la inversión extranjera debería estar construyendo nuevas fábricas, creando nuevas tecnologías y experiencias, pero eso no está sucediendo, lo cual sería un signo peligroso porque significa que los inversionistas extranjeros que quieran construir fábricas no están pensando en el Perú. "¿Por qué los extranjeros no construyen fábricas en el Perú? El experto responde que ello obedece a nuestra baja productividad, competitividad y un entorno muy favorable para hacer negocios. Esto tiene que ver por la pésima educación, mal sistema de salud, deficiente infraestructura física, la preocupante desigualdad social, alto nivel de corrupción y alto grado de informalidad"'.

Sin embargo, es digno mencionar que en a nivel del Gobierno Central, el tema está bajo estudio. Hay un proyecto en evaluación de fusionar la CONASEV y la SBS y AFP. Asimismo, en esa misma línea de pensamiento se ha integrado las Bolsas de Valores de Lima, con Bogotá y Santiago de Chile, norma ya aprobada y que empezarán a operar en forma integrada a partir del 22 de Noviembre de 2010. Unión que convertirá al Perú, Chile y Colombia en el primer mercado de América Latina con cerca de quinientas empresas listadas, superando a las plazas de Brasil y México ${ }^{10}$.

\section{Fortalezas de nuestra economía}

Adicionalmente debemos reconocer las siguientes ventajas del manejo de nuestra economía:

a) Tiene un robusto crecimiento económico, ininterrumpido desde hace ll (once), años.

b) Se proyecta un crecimiento para el 2010 de no menor del $6 \%$ cuando el mundo lo hará en promedio al $3 \%$.

c) Tiene un nivel de deuda pública de sólo $23 \%$ históricamente meritorio, que ha reducido a la mitad en sólo una década.

d) Tiene un nivel de inflación completamente controlado y de igual expectativa futura.

e) Tiene una moneda que se fortalece cada vez más en el tiempo.

f) Tiene cuentas externas financiadas y más de y más de 41,800 millones de dólares en Reservas Internacionales Netas (RIN). (Colombia tiene 25,000, Chile 26,000, Venezuela 29,000).

g) Tiene niveles de inversión de inversión privada del orden de 40,000 millones de dólares para los próximos 18 meses y se proyecta a crecer en más del $10 \%$ los siguientes años, asegurando así el crecimiento del empleo y el consumo en forma sostenida.

h) Tiene TLC firmados con todos los países ricos del mundo.

i) Exporta más de lo que importa.

j) Tiene grado de inversión, sólo junto a Brasil y Chile en la región.

Por consiguiente, sólo resta a nuestra economía, ayudar a crecer la Bolsa de Valores. Razones más que suficientes para tomar medidas correctivas para impulsar nuestro mercado de capitales.

8 Felipe Morris, Pablo Secada y Javier. “Análisis y Propuestas de Reforma del Merado de Capitales en el Perú”. (Noviembre 2007).

9 Michael Porter. “Inversión Extranjera en el Perú no Viene a Construir Fábricas”. (30/11/2009)

10 http://semanaeconomica.com "Integración de bolsas de valores de Lima, Colombia y Santiago empezará en noviembre“. 


\section{CAPÍTULO II. CUÁLES SON LAS ÁREAS ESTRATÉGICAS EN EL PERÚ}

\section{A. NUESTRA CONSTITUCIÓN Y LA BUENA VECINDAD}

El objetivo de esta investigación es crear conciencia en el sentido de reservar los sectores estratégicos con presencia obligada del capital nacional con financiamiento en la Bolsa de Valores de Lima; y aprovechar la oportunidad para desarrollar el mercado de capitales, buscando la transparencia en la información financiera a que están obligadas las empresas inscritas, como sociedades anónimas abiertas, para evitar a futuro que se repita el caso de Doe Run Perú, establecida como Sociedad Mercantil de Responsabilidad Limitada ${ }^{11}$.

La visión de empresas estratégicas, como política de estado, la manejan muy bien los países desarrollados. El Congreso Norteamericano la empleó para evitar la transferencia de empresas petroleras a capitales chinos, así como de puertos a inversionistas árabes, en pleno gobierno de George W. Bush, conspicuo representante del Partido Republicano. Asimismo, los franceses decidieron la participación estatal en su simbólica empresa energética Suez para impedir que el Estado italiano se hiciese de ella por una operación bursátil, lo que se inició durante el mandato de Jacques Chirac y fue culminada por el actual presidente Nicolás Sarkozy, ambos de orientación pro empresarial. Por tanto, el nacionalismo esta vivito y coleando en pleno Tercer Milenio.

El tema en cuestión son las inversiones provenientes de recursos de empresarios de países limítrofes, tópico que también se dis- cute en las principales naciones del orbe. ${ }^{12}$ En el caso de nuestro vecino del sur, el monto invertido es significativo, el acumulado desde la apertura irrestricta e irreflexiva de los años 90 hasta la fecha es del orden de los 7.200 millones de dólares, monto que equivale a siete plantas petroquímicas como las que se proyecta construir en la ciudad sureña de Marcona.

En sectores como electricidad, venta de combustibles y puertos la cosa es más complicada de lo que aparenta. No basta con decir que en caso de un conflicto internacional el Estado tiene todo el derecho de gestionar el manejo de las empresas, lo que no pasa de ser un buen deseo de una candidez suprema. Es indispensable que exista una serie de condiciones mínimas para tener una operación sin alteraciones, la lista de los puntos críticos es extensa y es indispensable que sea observada con detenimiento por expertos que orienten a las autoridades políticas y militares y que les hagan ver que no solo se trata de actos de compra-venta de acciones. Problema claramente expuesto y que invita a reflexión pensando en los intereses generales del país.

Según el periódico "Gestión"13, la relación económica entre Perú y Chile sigue siendo uno de los lazos más fuertes entre ambos países, presentando los capitales chilenos una participación cada vez más diversificada en el país. Informaciones del Ministerio de Relaciones Exteriores de Chile detalla que en el primer semestre del 2010 el Perú fue el principal receptor de inversión chilena directa con un monto de US\$ 1,232 millones. Con este resultado, el mercado peruano se consolida como el tercer destino de las inversiones directas de capitales chilenos en el

11 En el Perú, sólo las Sociedades Anónimas Abiertas, tienen la obligación de publicar trimestralmente sus Estados Financieros.

12 César Gutiérrez Peña. "Inversiones Estratégicas de Chile en el Perú“. Diario "La Razón“. 19.11.09. Lima. Perú.

13 "Perú es el primer país receptor de inversión chilena en primer semestre“. 17.08.10. Lima. Perú. 
exterior. Pues a junio de este año, éstas totalizaron US\$ 9,402 millones, lo que representa un $17.3 \%$ del total en el exterior.

A nivel de sectores, la actividad de servicios es el principal receptor de inversiones chilenas, con un monto acumulado de US\$ 4,798 millones, esto es, $51 \%$ del total invertido. El comercio (retail), sigue como uno de los subsectores que mayor crecimiento experimentó en los últimos años, con un monto de inversión acumulado de US\$2,080 millones (Cuadro N. ${ }^{0} 1$ ).

Nuestra Constitución Política del Año $1993^{14}$ en su Título III referido al Régimen Económico en su Capítulo I, expresa lo siguiente:

\section{PRINCIPIOS GENERALES}

Artículo $5^{\circ}$. La iniciativa privada es libre. Se ejerce en una economía social de mercado. Bajo este régimen, el Estado orienta el desarrollo del país, y actúa principalmente en las áreas de promoción de empleo, salud, educación, seguridad, servicios públicos e infraestructura.

Artículo 59 ${ }^{\circ}$. El Estado estimula la creación de riqueza y garantiza la libertad de trabajo y la libertad de empresa, comercio e industria. El ejercicio de estas libertades no debe ser lesivo a la moral, ni a la salud, ni a la seguridad pública. El Estado brinda oportunidades de superación a los sectores que sufren cualquier desigualdad; en tal sentido, promueve las pequeñas empresas en todas sus modalidades.

Artículo $60^{\circ}$. El Estado reconoce el pluralismo económico. La economía nacional se sustenta en la coexistencia de diversas formas de propiedad y de empresa.

Sólo autorizado por ley expresa, el Estado puede realizar subsidiariamente actividad empresarial, directa o indirecta, por razón de alto interés público o de manifiesta conveniencia nacional.

La actividad empresarial, pública o no pública, recibe el mismo tratamiento legal.

Artículo $61^{\circ}$. El Estado facilita y vigila la libre competencia. Combate toda práctica que la limite y el abuso de posiciones dominantes o monopólicas. Ninguna ley ni concertación puede autorizar ni establecer monopolios.

La prensa, la radio, la televisión y los demás medios de expresión y comunicación social; y, en general, las empresas, los bienes

Cuadro N.o 1. Inversión directa de chile en el Perú

\begin{tabular}{|l|c|c|c|c|}
\hline \multicolumn{1}{|c|}{ MACROSECTOR } & TOTAL IED & $(\%)$ & $\begin{array}{c}\text { EMPLEO } \\
\text { DIRECTO }\end{array}$ & $\begin{array}{c}\text { EMPLEO } \\
\text { INDIRECTO }\end{array}$ \\
\hline Servicios (3) & 4,798 & 51.0 & 48,862 & 0 \\
\hline Energía (1) & 2,909 & 30.9 & 07,070 \\
\hline Industria & 1,564 & 16.6 & 0,932 & 0 \\
\hline Minería (2) & 108 & 1.2 & 0 & 0 \\
\hline Agropecuario & 23 & 100.0 & 57,794 & 19,345 \\
\hline TOTAL GENERAL & 9,402 & 17.3 & & 0 \\
\hline PARTICIPACIÓN/ MUNDO & \multicolumn{2}{|c|}{} \\
\hline $\begin{array}{l}\text { (1) Incluye suministro de gas y agua; generación y distribución de electricidad. } \\
\text { (2) Incluye hidrocarburos; petróleo y gas. } \\
\text { (3) Incluye construcción, comercio (retail), hoteles y restaurantes, transporte y comunicaciones, servicios financieros, in- } \\
\text { mobiliarios, tecnología de la información, otros servicios profesionales }\end{array}$ \\
\hline
\end{tabular}

Fuente: Direcon. Departamento de Inversiones en el Exterior.

14 Tribunal Constitucional. Gobierno del Perú. Año 1993 
y servicios relacionados con la libertad de expresión y de comunicación, no pueden ser objeto de exclusividad, monopolio ni acaparamiento, directa ni indirectamente, por parte del Estado ni de particulares.

Artículo $62^{\circ}$. La libertad de contratar garantiza que las partes pueden pactar válidamente según las normas vigentes al tiempo del contrato. Los términos contractuales no pueden ser modificados por leyes u otras disposiciones de cualquier clase. Los conflictos derivados de la relación contractual sólo se solucionan en la vía arbitral o en la judicial, según los mecanismos de protección previstos en el contrato o contemplados en la ley.

Mediante contratos-ley, el Estado puede establecer garantías y otorgar seguridades. No pueden ser modificados legislativamente, sin perjuicio de la protección a que se refiere el párrafo precedente.

Artículo $63^{\circ}$. La inversión nacional y la extranjera se sujetan a las mismas condiciones. La producción de bienes y servicios y el comercio exterior son libres. Si otro país o países adoptan medidas proteccionistas o discriminatorias que perjudiquen el interés nacional, el Estado puede, en defensa de éste, adoptar medidas análogas.

En todo contrato del Estado y de las personas de derecho público con extranjeros domiciliados consta el sometimiento de éstos a las leyes y órganos jurisdiccionales de la República y su renuncia a toda reclamación diplomática. Pueden ser exceptuados de la jurisdicción nacional los contratos de carácter financiero.

El Estado y las demás personas de derecho público pueden someter las controversias derivadas de relación contractual a tribunales constituidos en virtud de tratados en vigor. Pueden también someterlas a arbitraje nacional o internacional, en la forma en que lo disponga la ley.

Artículo $64^{\circ}$. El Estado garantiza la libre tenencia y disposición de moneda extranjera.

Artículo $65^{\circ}$. El Estado defiende el interés de los consumidores y usuarios. Para tal efecto garantiza el derecho a la información sobre los bienes y servicios que se encuentran a su disposición en el mercado. Asimismo vela, en particular, por la salud y la seguridad de la población.

Analizando estos artículos encontramos que nuestra Ley de Leyes, debilita al Estado en sus atribuciones naturales de regulador de la actividad económica del país y de defensa de sus recursos naturales; suprime la planificación concertada y elimina los conceptos de interés social, la supervisión de la inversión extranjera y la importancia prioritaria del agro.

\section{FUNCIONES DEL ESTADO PE- RUANO SEGÚN LA CONSTITUCIÓN VIGENTE}

Promoción de Empleo. En este campo tenemos el grave problema de la informalidad. Analicemos lo que se dice a continuación ${ }^{15}$ :

"En el Perú existen más de veinte millones de personas en edad de trabajar (mayores de 14 años), pero de ellas solamente 13.5 millones forman parte de la Población Económicamente Activa (PEA), es decir, participan en la actividad económica ya sea como ocupado o buscando empleo". "Pero del total de personas que están ocupadas, más de tres cuartas partes laboran de manera informal, ganando sueldos que en algunos casos no se aproximan a la Remuneración Mínima Vital de S/.550 al mes”. “¿Cuántos trabajadores informales hay en el país? Tomando en con-

15 Alfredo Prado.“Un trabajador Formal gana dos veces más que un informal en el Perú“. Diario “Gestión“ 05.07.2010. Lima. Perú 
sideración que los que actualmente aportan al Sistema Nacional de Pensiones (ONP), son 1.2 millones de afiliados y los que cotizan efectivamente al Sistema Privado de Pensiones son 1.8 millones, la informalidad se acerca al $78 \%$ de los trabajadores".....Y en el ámbito rural la informalidad superaría largamente el $90 \%$ de los trabajadores, mientras que en el ámbito urbano estaría alrededor de un $70 \%$ ".

Un reciente documento de trabajo del Banco Central de Reserva del Perú ${ }^{16}$, que según dato de la Encuesta Nacional de Hogares (ENAHO), del 2007, un trabajador asalariado formal tiene un ingreso por hora de S/.9.10 mientras que uno informal gana un poco más que la tercera parte, apenas S/.3.20; (es decir, el trabajador formal gana $184 \%$ más que el trabajador informal). Si asumimos los supuestos clásicos de competencia en el mercado laboral -refiere el documento- esta diferencia estaría vinculada a distintos niveles de productividad de los trabajadores formales e informales, así como a las características del individuo como de la empresa. En ese sentido, si un empleado formal trabaja en una empresa muy intensiva en el uso del capital y de tecnología, su remuneración será largamente superior a la de otro que trabaja en una MYPE informal. $Y$ en los casos en que existan salarios distintos para trabajadores con características similares, estarían explicados por factores que segmentan el mercado laboral: información incompleta, información imperfecta, existencia de salarios mínimos, costos de movilidad laboral o ubicación geográfica.

Las mayores brechas entre las remuneraciones de los trabajadores formales e informales se estaría dando en el sector comercio y servicios, sectores precisamente donde la informalidad es muy alta. El BCRP refiere que las políticas para combatir la informalidad se dividirían en las dirigidas a elevar la productividad de los trabajadores y las dirigidas a reducir las fallas del mercado laboral. Entre las primeras destacarían los incentivos a la educación y a la capacitación laboral; la facilitación del acceso al crédito a las MYPES. Entre las segundas está el fomento de la Bolsa de Empleos y la reducción de los costos de contratación y despido para mayor movilidad laboral. Se nota pues, ausencia de claras políticas laborales en el país en beneficio de la masa trabajadora nacional.

Salud Pública. El Gobierno de turno percibe que es importante el factor social, anunció como gran logro de su gestión el Aseguramiento Universal en Salud. (AUS), afirmando que los nuevos afiliados tienen las atenciones garantizadas porque, desde ahora, todos los prestadores de salud (Minsa, Essalud, FF.AA, PNP y privados), trabajarán coordinadamente para brindar las atenciones. Sin embargo, el proceso de implementación aún no se ha realizado. Para eso se requiere homogeneizar los costos y modelos de atención, además, comprometer decididamente el financiamiento para las atenciones. De lo contrario, la situación seguirá como hoy se da. Lamentablemente, no se ha enfocado el tema de la salud de manera integral. Sólo se ha mencionado la atención en los servicios pero no en los temas de prevención.

Educación Pública. Otra cuestión fundamental es la mejora en la educación, que si bien se ha avanzado a nivel básico, no ha tenido el mismo desempeño en los demás niveles como la remuneración a los Docentes Universitarios, lo que en el futuro será uno de los problemas que nos impedirá crecer más. Esas

16 Daniel Barco y Paola Vargas. "Brechas Salariales entre Formales de Informales“. Banco Central de Reserva del Perú. Serie de Documentos de Trabajo. Mayo 2010. 
reformas postergadas era el camino prudente para lograr la empatía con aquellos peruanos que no sienten que el actual crecimiento los ha beneficiado ni que el Presidente se ha preocupado principalmente por ellos. La redistribución de la riqueza resulta así otro tema pendiente de solución.

Seguridad Ciudadana. En cuanto a seguridad ciudadana, el Gobierno no ha sintonizado con la preocupación de los peruanos. Se ha centrado más en pedir coordinación entre los Municipios y la Policía Nacional. Especialistas en temas municipales dicen que desde el año 2003, existe una norma que establece mecanismos para que ambas instituciones trabajen coordinadamente, pero que no se cumple. En la realidad es que sólo el $12 \%$ de Distritos del total de comunas en el país cuentan con un Plan de Seguridad Ciudadana, "porque muchos Alcaldes quieren manejar sólos su "serenazgo". Sin embargo, el tema de fondo está en el sistema pernicioso de trabajo que tienen los efectivos policiales: de dos días de trabajo por dos días de descanso. La lucha contra la delincuencia no es un asunto del Ministro del Interior ni del Alcalde Metropolitano, requiere de una respuesta de primer nivel y en muchos frentes simultáneamente. Se dice que tendremos más policías en las calles, pero lograremos minimizar esta lacra cuando los agentes tengan un desempeño diario y no esporádico, con el sistema de $24 \times 24$.

Servicios Públicos e Infraestructura. La intervención del Estado debe continuar siendo estrictamente de carácter regulador y promotor, como un apoyo y no como un obstáculo que se puede dar a través de leyes que desfavorecen a los inversionistas extranjeros o con mecanismos inestables que no le aseguren la protección de su dinero. Incentivar la reinversión para que los capitales ganados por las empresas extranjeras no salgan del país y sean invertidos en nuevos negocios que generen empleo y contribuyan al mejoramiento de la calidad de vida de los peruanos, debe ser una política de estado en el Perú si es que deseamos mantener nuestro crecimiento y desarrollo en el largo plazo.

\section{2. ¿EL PERÚ ES UNA ECONOMÍA SO- CIAL DE MERCADO?}

En el caso del Perú, es necesario recordar que tanto la Constitución de 1979 (Art. $115^{\circ}$ ), como la de 1993 en su artículo 58, establecen que «la iniciativa privada es libre» y que «se ejerce en una economía social de mercado». Además los grupos políticos que participaron en el Acuerdo Nacional, han aprobado varios compromisos, siendo uno de ellos la Política 17 sobre «Afirmación de la Economía Social de Mercado ». Por todo esto, amerita revisar los fundamentos de una economía social de mercado ${ }^{17}$.

Analicemos este concepto: 18 "La Economía Social de Mercado (ESM), tiene como objetivo el mantener un equilibrio entre un alto índice del crecimiento económico, baja inflación, bajo nivel de desempleo, buenas condiciones laborales, bienestar social, y servicios públicos, por medio de una economía de libre mercado y políticas públicas tendientes a mantener esa competitividad sumado a políticas sociales paliativas".

"En una Economía Social de Mercado, los contratos colectivos de trabajo están frecuentemente organizados a nivel nacional, pero no entre corporaciones, sino entre organizaciones nacionales de empresarios y sindicatos nacionales".

\footnotetext{
17 David Ordinola Boyer. "Economía Social de Mercado un Modelo para el Perú“.Cuaderno de Formación 4- 2006. Instituto de Estudios Social Cristianos. Lima. Perú.

18 http://es.wikipedia.org. Modelo de la Economía Social de Mercado.
} 
Importantes figuras en el desarrollo del concepto son Franz Oppenheimer, Walter Eucken, Wilhelm Röpke, Franz Böhm y Alfred Müller-Armack. Parte importante de la teoría también se debe al trabajo de la Escuela de Friburgo, a la cual pertenecían varios de los personajes citados anteriormente.

\section{PRINCIPIOS Y LÍMITES DE UNA ECONOMÍA SOCIAL DE MERCADO}

Para Alfred Müller-Armack, quien originalmente acuñó el término Soziale Marktwirtschaft, ${ }^{19}$ la Economía Social de Mercado requiere la observancia y cumplimiento de siete principios fundamentales:

- Sistema de precios cercano a la competencia perfecta

- Estabilidad de la moneda

- Acceso libre a los mercados

- Propiedad privada

- Libertad contractual

- Plena responsabilidad de políticas fiscales

- Transparencia económica

Los cuales debían tener como límites, cinco principios reguladores:

- Control estatal de monopolios

- Políticas redistributiva de ingresos

- Reglamentación del trabajo

- Garantía jurídica

- Salario mínimo.

Si comparamos con nuestra realidad, no encontramos parámetros parecidos al modelo que se describe líneas arriba, especialmente en el cumplimiento de los siete principios a excepción de: estabilidad de la moneda, acceso libre a los mercados, respeto a la propiedad privada y libertad contractual. Pero no hay límites reguladores como por ejemplo en política redistributiva de ingresos, actualización del salario mínimo (que ya lleva más de dos años sin haberse incrementado pese a una acumulación del $11 \%$ de inflación interna) y garantía jurídica para todos. El publicitado crecimiento económico que permanentemente nos recuerda el gobierno de turno, sólo representa a las minorías dominantes, en tanto que los trabajadores siguen sin progresar, lo que pone en grave riesgo la paz social del país.

\section{ACTIVIDADES ESTRATÉGICAS QUE DEBE PROTEGER EL ESTADO PERUANO}

Una de las críticas fundamentales al modelo económico peruano, aplicado por el Gobierno de turno, es que mediante la apertura irrestricta del mercado nacional a la inversión extranjera puede lograrse un crecimiento económico sostenido. Esto se plasma en el Art. 63 de la Constitución de 1993, que dice: "la inversión nacional y la extranjera se sujetan a las mismas condiciones". Así la inversión extranjera puede entrar a cualquier sector económico, desde el petróleo, la minería, la petroquímica, las líneas aéreas, los puertos, el sector financiero, las telecomunicaciones, etc. En esta visión, no existen sectores ni empresas estratégicas, por tanto, el Estado debe sustraerse de cualquier injerencia o tentativa de regulación.

En nuestra opinión, el Estado Peruano tiene la obligación de proteger, por razones de interés público y seguridad nacional, las siguientes áreas que denominamos estratégicas:
a. Agua y Saneamiento.
b. Energía Eléctrica e Hidroeléctrica
c. Gas
d. Hidrocarburos.
e. Investigación y Desarrollo.
f. Puertos y Aeropuertos.

19 Friedrich, Carl J. 1955. "The Political Thought of Neo-Liberalism”. American Political Science Review 49. 509-525. 
Áreas que influyen directamente en la aceleración del desarrollo político-económico y social del país, si son planificadas y ejecutadas con eficiencia y eficacia.

CAPÍTULO III. SITUACIÓN ACTUAL Y PERSPECTIVAS DEL FINANCIAMIENTO EN EL MERCADO DE CAPITALES.

\section{A. EL TERMÓMETRO DE LA BOLSA DE VALORES DE LIMA}

El mercado de valores está subdividido por el mercado primario y el mercado secundario. A diferencia del sistema financiero en el que se vende dinero, en el mercado de valores el objeto de negociación son los valores mobiliarios (acciones, bonos, instrumentos de corto plazo, etc.),

En el mercado primario las empresas emiten valores por primera vez, con la finalidad de ofrecerlo a los inversionistas y captar recursos. Y en el mercado secundario, que es la Bolsa de Valores, se transan valores que ya fueron previamente emitidos en el mercado primario. Las empresas también pueden inscribir sus acciones en bolsa en forma directa, sin necesidad de realizar una emisión de acciones. Con la finalidad que sus accionistas tengan la posibilidad de venderlas cuando requieran liquidez.

Según la Comisión Supervisora de Empresas y Valores (CONASEV), de las 215 empresas que hoy listan sus acciones en la Bolsa de Valores de Lima (BVL), menos del $30 \%$ se ha financiado en la bolsa. Pues las han inscrito para tener la oportunidad de venderlas cuando necesiten disponibilidad. A pesar de ello, las acciones que han negociado al menos el monto mínimo permitido por la CONASEV, han obtenido una rentabilidad máxima en los últimos 10 años del 5.106\% y en los últimos 5 años, de $2.125 \%$.
¿Entonces cuál es la ventaja? Estas empresas que están en vitrina tienen la mayor facilidad para captar recursos a través del mercado de valores, incurriendo en menores costos que prestar al banco. Sin embargo, por desconocimiento del mercado, por temor a lo nuevo, no captan recursos a través del mercado de valores. Hoy, (Julio del 2010), menos del $1 \%$ de las empresas grandes y medianas se financian en el mercado de valores, a través de la Bolsa, porque la mayoría no quiere hacer pública su información o porque están mal gestionadas. Se trata de empresas familiares que no saben separar la parte familiar de la figura jurídica, es decir, la práctica del principio generalmente aceptado de contabilidad denominado "Ente", que dice: "que las actividades de los accionistas son independientes de las actividades de la empresa”.

El empresario peruano prefiere el financiamiento vía valores de renta fija, tipo bonos corporativos. Porque teme cambiar la composición de su Junta de Accionistas. El Bono aumenta su endeudamiento y no cambia la estructura de su Junta General de Accionistas. Mientras que la emisión de acciones, incrementa su capital propio y amplía la composición de la Junta General de Accionistas. Estrategia que debe cambiar paulatinamente si el empresario medio aspira a globalizar su empresa y proyectarse al mundo entero vía exportación de sus productos.

Con honradas excepciones, lenta pero segura surge una nueva clase empresarial peruana. Al observar empresas como Ajegroup (Añaños), TopyTop (Flores), Perhusa (Perales Huancaruna), entre otras, fueron construidas por familias que escapan a los tradicionales grupos empresariales de nuestro país. Se trata de apellidos relativamente nuevos, no tan conocidos históricamente en el mundo corporativo peruano, se trata de familias sin mayor "abolengo" o "historia 
empresarial" previa. Son empresas y grupos que crecieron a una gran velocidad desde la década pasada y en la presente. Se trata de grupos que surgen de iniciativas de empresarios y familias de origen provinciano, que surgieron del interior de nuestro país. Están asumiendo progresivamente un mayor protagonismo en la sociedad peruana. Muchas tienden a la diversificación relacionada al "core business" ${ }^{20}$ original, como su estrategia principal de crecimiento, a diferencia de los Grupos Tradicionales como Romero o Brescia cuyas principales ventajas se basan en las "economías de escala" y de "enfoque" que sus diversificaciones no relacionadas les permiten, es decir, conglomerados que participan en varios mercados al mismo tiempo, siguiendo el "modelo de cartera" buscando minimizar los riesgos.

Algunas de estas familias, que saben cuán importante es la preparación para el futuro, están capacitando a sus nuevas generaciones en las mejores universidades nacionales e internacionales; lo que les permite emplear herramientas profesionales de gestión y a contratar a gerentes especializados con excelentes remuneraciones de nivel internacional.

\section{EL MITO SUPERADO}

Antes había un mito que a través del mercado de valores sólo se pueden financiar las grandes empresas. Sin embargo, en los últimos tiempos han capitalizado Corporación Miski, Tiendas EFE y Metalpren. Tiendas EFE es una comercializadora de electrodomésticos que fue autorizada por la CONASEV a emitir instrumentos de corto plazo por US\$ 4 millones, en el 2006. En dicho año, sus activos ascendieron a S/. 64.6 millones, y ahora en el 2010, son de S/.110.7 millones. Porque tiene más fondos de maniobra para comprar mercaderías a más bajos costos, y ofrecer productos más asequibles para sus clientes. Pero no debemos perder de vista que su desarrollo empresarial se ampara en el capital ajeno.

Pero las ventajas de esta modalidad de financiamiento saltan a la vista:

1. El Mercado de Valores (MV), permite a las organizaciones contar con diversas alternativas de financiamiento a través de la emisión de diversos valores mobiliarios.

2. Permite a la empresa determinar su requerimiento de financiación, en función de las características de sus planes de crecimiento y desarrollo.

3. Consiente a la empresa adecuar sus plazos de pago y fijar las tasas de interés que quiere pagar, además la moneda en que se quiere salir.

4. Crea historial crediticio a la empresa. Si en una primera emisión muestra un buen comportamiento de pagos, en una segunda emisión los costos se reducen.

5. Finalmente, crea imagen a la empresa ante sus potenciales acreedores y proveedores (Cuadro No 2).

\section{FINANCIAMIENTO MEDIANTE LA EMISIÓN DE ACCIONES}

Pero analicemos el otro lado de la medalla, cuando las empresas buscan financiar su desarrollo basando su crecimiento en la emisión de acciones vía la Bolsa de Valores sea nacional o extranjera. Un reciente estudio publicado por Gerens Escuela de Gestión y Economía $^{21}$, da cuenta que el 2009 no fue un buen año para la industria minera global y

20 Corazón del negocio. Conjunto de actividades que realiza una empresa y que la caracterizan, definen y diferencian en mercado y donde más valor aporta a la empresa.

21 Rentabilidad y Creación de Valor en la Industria Minera Global 2010. Publicado en Diario "Gestión“. 23.07.2010. Página 23. Lima. Perú. 
Cuadro N.o 2. Costos de transacción de emisiones de deuda (aproximado)

\begin{tabular}{|c|c|c|}
\hline \multicolumn{3}{|c|}{ EMISIÓN DE BONOS POR PRIMERA VEZ } \\
\hline Mlls.US\$ & Tasa Mínima (\%) & Tasa Máxima (\%) \\
\hline 5.0 & 3.13 & 5.47 \\
\hline 10.0 & 1.74 & 3.27 \\
\hline \multicolumn{3}{|c|}{ EMISIÓN DE BONOS POR SEGUNDA VEZ } \\
\hline 5.0 & 0.71 & 1.30 \\
\hline 10.0 & 0.57 & 1.20 \\
\hline \multicolumn{3}{|c|}{ EMISIÓN INSTRUMENTOS CORTO PLAZO POR PRIMERA VEZ } \\
\hline Mlls. US\$ & Tasa Promedio & \\
\hline 1.0 & 10.46 & \\
\hline 5.0 & 2.56 & \\
\hline \multicolumn{3}{|c|}{ EMISIÓN INSTRUMENTOS CORTO PLAZO POR SEGUNDA VEZ } \\
\hline 1.0 & 1.30 & \\
\hline 5.0 & 0.51 & \\
\hline
\end{tabular}

Fuente: CONASEV.

esto se reflejó en su rentabilidad patrimonial de las empresas que alcanzó $17 \%$. Sin embargo, para las empresas mineras peruanas inscritas en el Registro de Valores de Lima (RVL), el panorama fue otro. En efecto, las mineras locales lograron una rentabilidad de $29.7 \%$ el año pasado, así lo dio a conocer Rodrigo Prialé, Director Gerente de Gerens Escuela de Gestión y Economía. Precisó que estos resultados provienen del estudio de 41 empresas mineras del mundo, las que registraron a fines del 2009 el mayor valor de mercado en las bolsas de valores de EE.UU de N.A. y Londres. Entre las 10 empresas mineras con mayor rentabilidad patrimonial promedio 2005-2009 a nivel global figuran Southern Perú Copper y Compañía de Minas Buenaventura. La primera ocupó el puesto 19 en el ranking mundial de mineras con mayores ingresos del 2009, mientras Compañía de Minas Buenaventura se situó en la posición 32, según refiere el informe de Gerens.

\section{LISTANDO EMPRESAS EN LA BOL- SA DE VALORES DE LIMA (BVL)}

¿Cuál es el secreto de este éxito? Los beneficios de listar en la bolsa de valores. Analicemos a continuación una entrevista in extenso desarrollada al Sr. Roque Benavides Ganoza, actual Gerente General de Compañía de Minas Buenaventura ${ }^{22}$ :

\section{Uno de los logros más importantes de Buenaventura fue su inscripción en la Bolsa de Valores de Nueva York. ¿Por qué?}

Inscribirse en la Bolsa de New York es globalizar el accionariado de la empresa, es tener un valor más cercano a la realidad de la empresa y de sus acciones. Pues el tener un termómetro más cercano es muy valioso para efectos de la eficiencia y performance ${ }^{23}$ de la gerencia y al inversionista le permite saber cuánto vale su patrimonio.

22 Los Beneficios de Listar en la Bolsa de Valores. Diario "Gestión“. 27.07.2010. Página 28. Lima. Perú.

23 Vocablo de origen anglosajón que significa simplemente "actuación" en el amplio sentido del término. 


\section{Su inscripción en la Bolsa local fue} importante?.

Buenaventura fue inscrito en la BVL en 1971, época en la que la liquidez era nula. Sin embargo, en los 90, muchos fondos internacionales invirtieron en Buenaventura a través de la BVL, y fue el primer paso para que en la Bolsa de Nueva York despierte el apetito por tener una acción como Buenaventura. La BVL cumplió un rol fundamental para que los fondos internacionales conozcan a Buenaventura. Luego ir a la Bolsa más grande fue más fácil.

\section{3. ¿̇e inscribieron en NYSE sólo para medirse?}

Buenaventura emitió acciones en la Bolsa de Nueva York, en 1996, y logró levantar un capital importante, que nos permitió contar con los recursos para desarrollar los proyectos en cartera y reducir significativamente el endeudamiento con el sistema bancario. El resultado final de todo esto fue una empresa más sólida con más proyectos, mucho más viable.

\section{Si no hubiera captado capital en la Bolsa, no habrían crecido tan rápido?}

Podemos tener la gente más capacitada, pero si no se tienen los recursos para invertir, tampoco podemos desarrollarnos. Es evidente que la inyección de capital que significa la inscripción y emisión en la Bolsa de Nueva York contribuyó al crecimiento de Buenaventura. Fortaleció la empresa. Permitió a Buenaventura focalizarse en proyectos más grandes y no estar preocupados en pensar de dónde se saca dinero para atender diversos aspectos.

\section{5. ¿Qué tan menos costoso es financiarse en la Bolsa?}

Cuando Buenaventura se inscribió en la Bolsa de Nueva York, los fondos de inver- sión ya conocían a la empresa. Entonces, ir a financiarse al mercado de valores con renta fija, por ejemplo, es un gran paso para hacerse conocido. El costo depende del riesgo de la empresa y esto se obtiene con el hecho de estar inscritos en una Bolsa.

\section{Si lo comparamos con los costos de la Banca... \\ Definitivamente, levantar capital tiene} un costo, de dilución, de valorización de la empresa. Hay mucha gente que considera que mejor es estar endeudado. El problema es que estar sobre endeudado también pone en peligro a la empresa. Hoy Buenaventura por efecto de la emisión de capital que hizo en 1996, no ha tenido que recurrir a los mercados financieros para levantar deuda. Hasta el día de hoy seguimos operando sin deuda.

\section{Qué tanto valor ha ganado la compa- ñía en el tiempo?}

Mucho. Lo que puedo decir es que el valor de Buenaventura ha aumentado seguramente entre 400 y 500 veces lo que era antes.

\section{8. ¿Es caro estar en Bolsa?}

Tiene que haber una masa crítica para estar en la Bolsa. Para una pequeña o microempresa seguramente es muy caro. No voy a decir que no cuesta, pero para hacer tortillas, hay que reventar los huevos. Entrar a la Bolsa tiene un costo. Sin embargo, los beneficios también son muy valiosos.

\section{9. ¿Qué cree que falta a la BVL?}

La BVL es una bolsa chica. La iniciativa de unirse con otras Bolsas es valiosa, porque haría una Bolsa más representativa. El hecho de que estén inscritas 215 empresas en la BVL demuestra que mucha gente no quiere informar al mercado como se tiene que hacer. No se dan cuenta del valor que tiene el 
hecho de estar en una Bolsa. Con el tiempo, conforme las empresas familiares crezcan se darán cuenta de que lo fundamental es darles a todos los miembros una cifra real de valor de la empresa.

El financiamiento a través del mercado de capitales, siempre resulta más beneficioso que acudir a la banca privada. Quizá la diferencia está en el foco que le ponen los empresarios al desarrollo de sus actividades: La sociedad anónima cerrada prefiere el endeudamiento de los bonos corporativos. Mientras que la sociedad anónima abierta, siempre optará, como es el caso de Buenaventura y otros, por la emisión de acciones. La debilidad de la primera estrategia está en el alto costo financiero que representa para las empresas, casi llega al 10\% de las ventas netas y con elevado riesgo. Sólo pueden conseguir rentabilidad operativa. Mientras que con la capitalización de acciones, se eleva la liquidez y la rentabilidad es por partida do- ble: financiera y operativa. Esta es la clave de éxito de las grandes corporaciones internacionales, que toman colosales decisiones con total autonomía sin necesidad de acudir a los banqueros tradicionales.

\section{PANORAMA FUTURO DE LAS GRANDES INVERSIONES}

Para entender la importancia del movimiento de capitales en juego que moviliza y movilizará en el futuro la economía peruana, publicamos a continuación la relación de los proyectos de inversión que tiene entre manos el Gobierno Central, que se resume en lo siguiente:

1) Tren Eléctrico. Culminación de la Línea 1.

2) Mejoramiento de Infraestructura de los Aeropuertos Nacionales.

3) Concesiones Viales IIRSA Sur y Norte. (Integración Infraestructura Regional Sudamericana).

Cuadro N.o 3. Principales proyectos de inversión del gobierno nacional (En Miles de Nuevos Soles)

\begin{tabular}{|l|c|c|c|}
\hline \multirow{2}{*}{\multicolumn{1}{|c|}{ PROYECTOS }} & \multicolumn{3}{c|}{ ENERO - JUNIO } \\
\cline { 2 - 4 } & $\mathbf{2 0 0 9}$ & $\mathbf{2 0 1 0}$ & VAR (\%) \\
\hline TRANSPORTES & $\mathbf{1} \mathbf{1 4 0 , 8 6 9}$ & $\mathbf{2} \mathbf{2 4 4 , 6 6 1}$ & $\mathbf{9 7}$ \\
\hline Concesiones Viales IIRSA & 609,318 & 854,821 & 40 \\
\hline Proyecto Especial Tren Eléctrico & 43 & 302,872 & 704,253 \\
\hline Rehabilitación y Mejoramiento Ayacucho-Abancay & 9,845 & 168,718 & 71 \\
\hline Rehabilitación y Mejoramiento Carretera Tingo María- Aguaytía -Pucallpa & 26,603 & 65,032 & 144 \\
\hline Rehabilitación y Mejoramiento Carretera Casma -Yuaytán -Huaraz & 19,346 & 50,810 & 163 \\
\hline Rehabilitación y Mejoramiento Churín - Oyón & 0 & 19,229 & 0 \\
\hline Rehabilitación y Mejoramiento Tarapoto - Juanjuy & 26,586 & 17,725 & -33 \\
\hline Concesiones Aeroportuarias Jorge Chávez y aeropuertos de Provincias & 43,137 & 407,643 & 845 \\
\hline Rehabilitación y Mejoramiento Carretera Lunahuaná - Desvío Yauyos-Chupaca & 18,909 & 14,820 & -22 \\
\hline Construcción de Pasos a Desnivel Autopista Ramiro Prialé & 0 & 20,748 & 0 \\
\hline Mejoramiento de la Red Vial Nacional & 1,651 & 23,688 & 1,335 \\
\hline Mejoramiento y Construcción de Carretera Reposo Saramiriza Eje Vial No. 4 & 36,770 & 20,329 & -45 \\
\hline Concesiones Portuarias - Muelle Sur del Callao & 1,130 & 8,080 & 615 \\
\hline Rehabilitación y Mejoramiento Desvío Tocache - Tocache & 55,931 & 16,566 & -70 \\
\hline Construcción y Mejoramiento Carretera Camaná-Matarani - Ilo - Tacna. & 617 & 30,750 & 4,884 \\
\hline Construcción y Mejoramiento Cuzco - Quillabamba & 0 & 38,401 & 0 \\
\hline
\end{tabular}




\begin{tabular}{|c|c|c|c|}
\hline Rehabilitación y Mejoramiento carretera Chongoyape - Cochabamba - Cajamarca & 19,474 & 2,486 & -87 \\
\hline Rehabilitación de Caminos Vecinales y Rurales & 60,348 & 41,389 & -31 \\
\hline Rehabilitación Integral Ferrocarril Huancayo - Huancavelica & 3,917 & 809 & -79 \\
\hline Construcción y Reforzamiento de Puentes & 13,819 & 11,569 & -16 \\
\hline Conservación y Rehabilitación de Carreteras & 5,717 & 32,618 & 471 \\
\hline Rehabilitación y Mejoramiento Carretera Nazca -Puquio - Chalhuanca - Abancay & 99 & 7,405 & 7,380 \\
\hline Rehabilitación y Mejoramiento Carretera Trujillo - Shirán - Huamachuco & 10,895 & 635 & -94 \\
\hline Rehabilitación, Mejoramiento y Construcción Eje Vial No. 1 Piura - Guayaquil & 34,129 & 4,651 & -86 \\
\hline Rehabilitación y Mejoramiento Casma-Huaraz & 16,874 & 0 & 0 \\
\hline Rehabilitación, Mejoramiento Ingenio-Chachapoyas & 4,754 & 2 & -100 \\
\hline Otros & 120,960 & 82,865 & -31 \\
\hline SALUD & 31,512 & 190,125 & 503 \\
\hline Mejoramiento y equipamiento del servicio de emergencia de Hospitales & 21,187 & 178,304 & 742 \\
\hline Programa de Apoyo al Sector Salud - PAR Salud & 4,344 & 2,095 & -52 \\
\hline Otros & 5,981 & 9,726 & 63 \\
\hline ELECTRICIDAD & 113,760 & 213,194 & 87 \\
\hline Instalación de Pequeños Sistemas Eléctricos en Diversos Poblados & 98,767 & 200,146 & 103 \\
\hline Mejoramiento de Líneas de Transmisión & 5,164 & 1,543 & -70 \\
\hline Otros & 9,829 & 11,505 & 17 \\
\hline AGROPECUARIO & 168,890 & 149,873 & -11 \\
\hline Infraestructura de Riego & 32,963 & 59,027 & 79 \\
\hline Apoyo al Sector Agrario & 87,961 & 55,033 & -37 \\
\hline Eliminación de la Mosca de la Fruta Ceratitis Capitata de la Costa Peruana & 15,900 & 2,631 & -83 \\
\hline Otros & 32,066 & 33,182 & 3 \\
\hline VIVIENDA & 100,470 & 168,637 & 68 \\
\hline Apoyo al Sector Habitacional & 53,866 & 79,254 & 47 \\
\hline Proyecto Nacional de Agua Potable y Saneamiento Rural & 26,823 & 54,798 & 104 \\
\hline Derechos de Propiedad Inmueble & 11,640 & 12,954 & 11 \\
\hline Otros & 8,141 & 21,631 & 166 \\
\hline ECONOMIA & 61,933 & 58,449 & -6 \\
\hline Asistencia Técnica y Evaluación & 24,209 & 20,536 & -15 \\
\hline Promoción de la Inversión Privada & 16,431 & 17,610 & 7 \\
\hline Otros & 21,293 & 20,303 & -5 \\
\hline JUSTICIA & 57,258 & 64,714 & 13 \\
\hline Mejoramiento Servicios Administración de Justicia & 39,076 & 50,912 & 30 \\
\hline Otros & 18,182 & 13,802 & -24 \\
\hline EDUCACIÓN & 166,250 & 268,389 & 61 \\
\hline Mejoramiento de la Infraestructura Educativa & 139,530 & 212,806 & 53 \\
\hline Otros & 26,720 & 55,583 & 108 \\
\hline OTROS & 311,349 & 348,129 & 12 \\
\hline Proyecto de Emergencia Social Productiva (PESP) & 10,957 & 26,450 & 141 \\
\hline Gestión de Proyectos & 86,531 & 85,551 & -1 \\
\hline Operación y Mantenimiento de Operaciones de Producción Agraria & 11,001 & 13,043 & 19 \\
\hline Otros & 202,860 & 223,085 & 10 \\
\hline TOTAL GENERAL & $2^{\prime} 152,291$ & $3^{\prime} 706,170$ & 72 \\
\hline
\end{tabular}


CAPÍTULO IV. PROPUESTA DE FINANCIAMIENTO DE LAS INVERSIONES ESTRATÉGICAS EN EL PERÚ.

\section{A. MERCADO DE CAPITALES COMO FUENTE DE FINANCIAMIENTO DE PROYECTOS DE INVERSIÓN DE IN- FRAESTRUCTURA PÚBLICA}

Un reciente informe procedente del Banco Central de Reservas del Perú (BCRP) ${ }^{24}$ sugiere: El mercado de capitales se puede constituir en una fuente de financiamiento de proyectos de inversión de infraestructura pública. Para ello, es necesario identificar los proyectos factibles de ser desarrollados por el sector privado a través de Asociaciones Público Privadas, y promover los procesos de concesión. El financiamiento se obtendría a través de la colocación de bonos en moneda nacional cuyo pago esté respaldado por los flujos de caja que genere el proyecto. Por ejemplo, el cobro de peajes en el caso de construcción de infraestructura vial.

Adicionalmente, estos flujos de caja deben estar garantizados por el Estado en el contrato de concesión, con lo que estos bonos alcanzarían las mejores calificaciones de riesgo y se disminuiría el costo del financiamiento, más aun si se considera que la deuda soberana de Perú cuenta con grado de inversión. La emisión de bonos para financiar infraestructura pública dinamizaría significativamente la oferta de valores en el mercado de capitales y serían muy demandados por los inversionistas institucionales con un perfil de largo plazo y por los fondos de inversión. En este sentido, el gobierno ha promovido la conformación de un fondo en infraestructura por US\$ 500 millones con la participación de las AFP, COFIDE y el BID. Adicionalmente, las AFP han comprometido US\$ 225 millones en un fondo de inversión en infraestructura administrado por el sector privado.

\section{Momento oportuno para potenciar desarrollo}

Se observan algunos factores adicionales que constituyen retos para el mercado de capitales pero que a su vez ofrecen oportunidades para potenciar su desarro1lo. Entre ellos, destacan los siguientes:

a. Reducida liquidez y profundidad del mercado de capitales. Este factor se explica por el reducido número de emisores y de emisiones como por el reducido monto de éstas, que determina que la adquisición de estos títulos en el mercado secundario por un inversionista institucional pueda tener efectos importantes en las cotizaciones. Además, la mayoría de los inversionistas institucionales que adquieren valores en el mercado primario lo hacen con la intención de mantenerlos al vencimiento ("buy and hold") dado su perfil de largo plazo y el riesgo de reinversión de los recursos ante la escasez de nuevas oportunidades de inversión. La industria de los fondos mutuos constituye el vehículo ideal para ampliar la base de inversionistas en el mercado de capitales, desconcentrando el dominio por el lado de la demanda que ejercen los inversionistas de largo plazo como las AFP. Una ventaja de los fondos mutuos es la diversidad de los mismos en función a distintos perfiles de riesgo, horizontes de inversión, etc. Así, el desarrollo de fondos mutuos de corto plazo o con un estilo más activo de inversión permitiría dotar al mercado secundario de deuda de mayor liquidez.

24 Reporte de Estabilidad Financiera. Mayo 2010. Banco Central de Reservas del Perú. Lima. Perú. 
De otro lado tenemos la diversificación del conocimiento financiero como $^{25}$ el auge de la ingeniería financiera que se produce cuando el conjunto de instrumentos financieros se hace más numeroso y, a su vez, los bancos e intermediarios financieros se hacen más activos tomando, en muchos casos, la iniciativa de ofrecer a los clientes las nuevas posibilidades de inversión y financiación proporcionadas por la innovación financiera. Todo ello se ha generado en un clima de competencia entre los distintos operadores: bancos, agentes de cambio, brokers, intermediarios financieros, etc., dentro de un sistema de interconexión de los mercados en donde desaparece la distinción entre el corto y el largo plazo, títulos y préstamos, fondos propios y deuda, etc. Si hubiera que fijar una sola razón por la que surge la ingeniería financiera esa sería la falta de estabilidad en el sistema de cambios, en los tipos de interés. En los mercados, en la solvencia de los países, y en resumen, un mayor riesgo en el conjunto de operaciones financieras y comerciales. $\mathrm{Mu}-$ chas empresas se han dado cuenta que esta inestabilidad puede causarles dificultades en la consecución de los flujos de caja previstos $y$, en algunos casos, llevarles a la quiebra o a tomas de control societario hostiles.

Todo ello ha creado la demanda de instrumentos financieros, que gestionen este tipo de riesgos. Por ello en 1985 ya existía un grupo de bancos en la City londinense que anunciaba

que "a través de la ingeniería financiera nosotros no evitamos el riesgo sino que lo gestionamos".

Los nuevos vientos de la globalización no sólo traen oportunidades sino también amenazas. Y entre ellas, está la volatilidad de los precios internacionales, a la que es necesario dar preferente importancia para minimizar el Riesgo Ambiental. Es decir, aquél que afecta a los resultados de una empresa debido a los cambios imprevistos en el ambiente económico en el que se desenvuelve la misma y que escapa totalmente a su control. Así que este riego deberá ser identificado y medido, puesto que la rentabilidad de una empresa no sólo depende de lo eficientes que sean sus directivos para controlar el riesgo propio del negocio de la compañía, sino que también dependerá de lo bien que controlen el riesgo ambiental.

\section{Inseguridades de ser empresa global}

Entre las inseguridades a las que está expuesta una empresa podemos destacar:

- Movimientos en los precios de las materias primas

- Variaciones en los tipos de cambio de las divisas en las que se denominan dichas materias primas

- Oscilaciones en el precio de la energía, que se necesita para procesar dichas materias

- Cambios en el tipo de cambio de su propia moneda (si aumenta, reducirá su competitividad en el exterior, ocurriendo lo contrario si desciende)

- Cambios en las tasas de interés de su país, que afectarán al coste de su endeudamiento $y$, posiblemente, a sus ingresos por ventas

- Alteraciones en los tipos de interés de otros países, que afectarán a sus competidores y, por lo tanto, al comportamiento de las ventas de la empresa, etc.

Considerando que nuestro país está alcanzando "la madurez financiera", por las necesidades que impone la construcción de

25 Sara Gonzáles y Juan Mascareñas. "La Globalización de los Mercados Financierops“. Universidad Complutense de Madrid. Noticias de la Unión Europea No. 172. Año 1999. Páginas 15-35 
la infraestructura física que adolece a nivel nacional, además del típico financiamiento que propone el Banco Central de Reserva del Perú, "a través de la colocación de bonos en moneda nacional cuyo pago esté respaldado por los flujos de caja que genere el proyecto, como es el cobro de peajes", es también importante promover el accionariado difundido en parte del financiamiento de los grandes proyecto en por lo menos un $30 \%$ que sea destinado a "levantar fondos en la Bolsa de Valores de Lima”, y exigiendo que dichas empresas se constituyan en el Perú exclusivamente como SOCIEDADES ANÓNIMAS ABIERTAS. Y sólo exoneradas de dicho requisito, cuando se demostrara que el mercado interno adolezca de capacidad de financiamiento. Para evitar en el futuro el caso lamentable de DOE RUN PERÚ, y/o como Lima Airport Partners, concesionaria del Aeropuerto "Jorge Chávez" de Lima, establecidas como Sociedad Comercial de Responsabilidad Limitada la primera, y como Sociedad de Responsabilidad Limitada la segunda, con la premeditada decisión de no informar al público usuario el movimiento de sus actividades.

\section{El ejemplo de petrobras}

La petrolera brasileña ${ }^{26}$ se convirtió en la cuarta empresa de capital abierto más valiosa del mundo gracias a una emisión de acciones sin precedentes en los mercados. La captación de 115.041 millones de reales (unos US\$66.900 millones) en una oferta pública de acciones registrada ante las autoridades reguladoras de Brasil elevó el valor de mercado de la mayor compañía brasileña a cerca de US\$220.000 millones.
Esa cifra solo es superada por gigantes como Exxon (US\$290.000 millones), PetroChina y Apple, según estudios de distintas firmas de consultoría con base en el cierre de los mercados esta semana. Pese a que el ministro brasileño de Hacienda, Guido Mantega, llegó a presentar hoy a PetroBras como la segunda empresa en valor de mercado de América, la brasileña está en tercera posición. Pero la valorización de Petrobras está más vinculada a su potencialidad que a su actual producción.

Para comenzar a extraer esa riqueza, PetroBras diseñó un ambicioso plan que prevé inversiones por US $\$ 224.000$ millones entre 2010 y 2014 y para el que necesitaba una inyección inicial de recursos que consiguió con su capitalización.

Según Mantega, Ministro de Economía de Brasil, la emisión de acciones le permitió al Estado aumentar su participación en el capital total de Petrobras del 40 al 48\%. El resto de acciones se negocia en las bolsas de Sao Paulo, Nueva York, Madrid y Buenos Aires. Lo irónico de esta información es que las AFP peruanas ${ }^{27}$ participaron en la gigantesca operación que se concretó anoche (23.09.2010). Al respecto, el gerente de inversiones de Profuturo AFP, Pedro Grados, comentó que las entidades previsionales siempre están atentas a oportunidades de adquirir títulos de buena factura como los de la petrolera brasileña. De acuerdo a la composición actual de sus portafolios y a los límites para invertir en el exterior, las AFP peruanas tienen unos US\$ 800 millones disponibles para adquirir valores extranjeros.

La venta de acciones ayudará a Petrobras a recaudar los fondos que necesita para pagar por el mayor plan de exploración de

26 www.dinero.com. Septiembre 2010. "Petrobras entre las mayores empresas del mundo“.

27 “AFP peruanaws participaron en la subasta récord de Petrobras“. Diario Gestiòn, página 26. 24.09.2010. Lima. Perú 
crudo del mundo, que pretende convertir a Brasil en una potencia energética global. Oferta que dará a PetroBras efectivo para su programa de inversión a cinco años por US\$ 224,000 millones.

Por consiguiente, qué mejor ejemplo que da la potencia brasileña para no imitarlo? El diario de mayor circulación calificó así la noticia ${ }^{28}$ : Ayer la empresa de mayoría accionaria estatal vendió 70,000 millones de dólares en acciones. Con ello registró la mayor oferta de títulos en la historia de la humanidad y, de paso, convirtió la Bolsa de Valores de Sao Paulo en la segunda mayor del mundo en valor de mercado, informó el presidente de la BM\&FBovespa, Edemir Pinto.

Un significativo ejemplo para indicarnos que el camino que debemos seguir para fortalecer nuestra Bolsa de Valores de Lima. Las Sociedades AA, publican sus balances en forma trimestral y practican el principio de transparencia. ¡SÓLO LA TRANSPARENCIA REDUCE LA CORRUPCIÒN!

El favorable contexto económico hace prever que el ahorro y las inversiones de los peruanos continuará creciendo en los próximos años, remodelando los mercados financieros y de capitales, afirma Melvin Escudero, presidente de El Dorado Investment ${ }^{29}$. Estima que el ahorro e inversión de los peruanos asciende a unos US\$ 70,000 millones, incluyendo los US\$ 13,000 millones que invierten en el extranjero. ¿Dónde se invertirán esos recursos de millones de peruanos, que buscan acumular un patrimonio para mejorar su calidad de vida en el futuro? La respuesta -dice- tiene que ver con el nivel de cultura financiera y con el destino final de estas inversiones: cubrir necesidades de liquidez, etc. Nuestro deseo, que deben volver al país a financiar los grandes proyectos que se listan para el largo plazo y su camino ideal, como el ejemplo brasileño: la Bolsa de Valores de Lima.

\section{Promoviendo accionariado difundido en el sector estratégico peruano}

Nuestra propuesta concreta es modificar el Artículo 60, tercer párrafo, de la Constitución Política vigente, en los siguientes términos: "La actividad empresarial, pública o no pública, recibe el mismo tratamiento legal. Pero las inversiones en los sectores: Agua y Saneamiento; Energía Eléctrica e Hidroeléctrica; Gas; Hidrocarburos; Investigación y Desarrollo; Puertos y Aeropuertos, se constituirán como Sociedades Anònimas Abiertas y tendrán la obligación de colocar un 20\% mìnimo de su capital social en la Bolsa de Valores de Lima”.

\section{CAPÍTULO V. CONCLUSIONES}

1) El desarrollo de las infraestructuras es clave para el progreso de un país. Dentro de una Economía Social de Mercado, como específicamente lo establece el artículo 58 de nuestra Constitución vigente, el Estado orienta el desarrollo del país, debe regular y defender sus recursos naturales por razones de interés público y seguridad nacional, priorizando las siguientes áreas:
a) Agua y Saneamiento.
b) Energía Eléctrica e Hidroeléctrica.
c) Gas
d) Hidrocarburos
e) Investigación y Desarrollo
f) Puertos y Aeropuertos.

28 Diario „"El Comercio“. "Petrobras concretó ayer la mayor oferta de acciones de la historia“. 25.09.2010. Página b11. Lima. Perú. 29 "Peruanos tienen inversiones en el exterior por US\$13,000 millones“. Diario "Gestión“. Página 14. 21.09.2010. Lima. Perú. 
En las empresas públicas y privadas se ha demostrado que la estrategia de diferenciación depende de su capacidad innovadora, y ésta a su vez del capital intelectual que han desarrollado. Para que las empresas, regiones y/o países puedan disponer de un capital intelectual importante tienen dos caminos: desarrollarlo (a un costo muy alto) o atraerlo. Es por esto que, somos testigos de una intensa competencia a nivel internacional para conservar y atraer la Inversión Extranjera Directa (IED), porque el Gobierno ha decidido el segundo camino: convivir con el capital global. Pero es necesario fijar las reglas en beneficio de la economía peruana.

2) El Modelo Peruano a diferencia de otros países, y que la hace atractiva al capital privado extranjero: es la ventaja de los contratos asociativos. Contratos que no generan una persona jurídica, y no están sujetos a inscripción en los RR. PP. ¿̇Por qué es atractivo el modelo? Porque no se aplica el Principio de Transparencia. El país no conoce sus resultados, sólo las autoridades competentes. No son Sociedades Anónimas Abiertas (SAA), por tanto, no están obligados a publicar trimestralmente sus EE.FF, en la BVL. No divulgan sus Informes de Auditoría Externa porque no tienen esa exigencia. Porque comparados con otros países no pagan impuestos a las sobre utilidades que puede llegar al 50\%, contra el 30\% que se cobra ahora. Por eso se presentan casos como el de Doe Run Perú.

3) Las alternativas de solución analizadas a lo largo de esta investigación, al margen de la tradicional emisión de bonos, quedan las siguientes:
a) Prestación de Servicios.
b) Arrendamientos.
c) Servicios de Gerencia.
d) Concesiones.
e) Empresas del Estado con acciona- riado difundido.

\section{f) Empresas privadas con accionaria- do difundido.}

Las únicas alternativas que contribuirían a elevar el nivel de inversión del mercado de valores peruanos serían las opciones e) y f) porque tienen costo cero para el inversionista.

4) Nuestra propuesta de financiamiento de las inversiones estratégicas sería la siguiente:

a) Para Empresas del Estado:.

Cualquier asociación público-privada que se autorice, las empresas tendrán la obligación de inscribir sus acciones en la BVL. Y puedan colocar en manos de inversionistas nacionales privados el $20 \%$ de su patrimonio.

b) Para Empresas Privadas:

Toda inversión que se realicen en el Perú, a partir de la fecha, deben constituirse como Sociedades Anónimas Abiertas (SAA), con la obligación de colocar el $20 \%$ de su patrimonio en la Bolsa de Valores de Lima (BVL), a favor de inversionistas nacionales residentes en el país. Porque se practica el principio de transparencia y sólo con ella será posible controlar los resultados económico-empresariales, y de paso, contribuir a reducir o minimizar la corrupción generalizada que aflige a nuestra patria.

\section{CAPÍTULO VI. RECOMENDACIONES}

1) Para llevar a la práctica la identificación de áreas estratégicas, cuyas empresas tengan la obligación de constituirse como Sociedades Anónimas Abiertas, es de necesidad pública promover este proceso, inscribiendo las empresas del Sector FONAFE, al más breve plazo, en la Bolsa de Valores de Lima, desarrollando una intensa campaña publicitaria que incentive el ahorro financiero. 
2) Con el llamado "Modelo Económico Peruano de Inversión", para minimizar o eliminar la corrupción, el Gobierno de Turno, tiene la oportunidad de promover las llamadas Sociedades Anónimas Abiertas que practican el principio de la TRANSPARENCIA, al estar obligadas a publicar trimestralmente sus Estados Financieros. Corresponde a CONASEV, promover los beneficios del accionariado difundido.

3) El accionariado difundido, es hacer de la participación ciudadana nacional una forma de redistribuir la riqueza del país. La vieja fórmula que una empresa privada se endeuda con un Banco, además de onerosa, debe desaparecer paulatinamente conforme se incremente la cultura del ahorro financiero.

Países como Argentina, Brasil, Colombia y Chile, con mayor o menor injerencia del Estado, coinciden en la importancia de promover la inversión con el apoyo de la empresa privada. $\mathrm{Y}$ el accionariado difundido resulta más fortalecido en toda la región, con el ejemplo que recientemente acaba de realizar PetroBras en el Brasil.

4) Tanto las empresas del Estado, como las privadas, residentes en el país, al optar por el accionariado difundido, obligan a las AFP`s a invertir sus excedentes en las futuras empresas a constituirse. Haciendo de paso posible que el ahorro nacional, fruto de los trabajadores peruanos, apoye a la empresa nacional. Y, viabilice de paso, la fusión de las Bolsas de Valores de Colombia, Chile y Perú que perfectamente podrían atraer capital fresco para nuevas inversiones a través de las alternativas aquí planteadas a lo largo de este trabajo de investigación.

\section{REFERENCIAS BIBLIOGRÁFICAS}

1. Alan García Pérez, en discurso dirigido a la Nación el 28 de Julio del 2010.

2. Ángela María Orozco Gómez. "Las Inversiones brasileras en Colombia“. Julio 2008. Página 5.

3. Alfredo Prado."Un trabajador Formal gana dos veces más que un informal en el Perú". Diario "Gestión“ 05.07.2010. Lima. Perú

4. Asociación Peruana de Consumidores y Usuarios ASPEC. „"El Transporte Aéreo de Pasajeros en el Perú y los Derechos de los Usuario". Pàgina 13-14. Lima. Perú.

5. Banco Central de Reserva del Perú. "Reporte de Estabilidad Financiera“. Mayo 2010. Lima. Perú.

6. Banco Central de Reserva del Perú. "Proyecta que la Inversión Extranjera Directa llegará a los US\$5,296 millones“. 21.06.2010. Lima. Peru.

7. Basombrío Muro, María Fernanda \& Otros. "Mercado de Líneas Aéreas".

8. Claudio Agostini. "La Organizaciòn Industrial del Transporte Aèreo en Chile“. Ilades. Universidad Alberto Hurtado. Santiago de Chile. Chile. Pàginas 52/54.

9. César Gutiérrez Peña. "Inversiones Estratégicas de Chile en el Perú“. Diario "La Razón“. 19.11.09. Lima. Perú.

10.Daniel Barco y Paola Vargas. "Brechas Salariales entre Formales de Informales". Banco Central de Reserva del Perú. Serie de Documentos de Trabajo. Mayo 2010.

11.David Ordinola Boyer. "Economía Social de Mercado un Modelo para el Perú“. Cuaderno de Formación 4-2006. Instituto de Estudios Social Cristianos. Lima. Perú. 
12. Delegaciòn de la Comisiòn Europea en el Perú.

13. Diario "Gestión". "Rentabilidad y Creación de Valor en la Industria Minera Global 2010“. 23.07.2010. Página 23. Lima. Perú.

14. Diario "Gestión"."Los Beneficios de Listar en la Bolsa de Valores“. 27.07.2010. Página 28. Lima. Perú.

15. Diario "Gestión". "Se Reaviva pugna entre las aerolineas y el concesionario LAP“, 9.08.2010. Lima. Perú.

16. Diario "Gestión". Wilfredo Huamanchin.." "Inversiones Elèctricas sumaron US\$ 491.8 mlls., en el primer semestre“. Página 11. 17.08.2010. Lima. Perú

17. Diario "Gestión". "Concentración en la economía y abuso de posición de dominio“. 20.08.10. Lima. Perú.

18. Diario "Gestión". Sonia Gilvonio M. "Se abre el camino para la venta de acciones de las empresas públicas“.“. 31.08.2010. Pàgina 4. Lima. Perù.

19. Diario "Gestión" "Peruanos tienen inversiones en el exterior por US\$13,000 millones“. Página 14. 21.09.2010. Lima. Perú.

20. Diario "Gestión". AFP peruanas participaron en la subasta récord de Petrobras"., página 26. 24.09.2010. Lima. Perú.

21. Efraín Gonzales de Olarte."Economía Política de la Reforma del Estado en el Perú”. 17.04.206.

22. Entrevista a Pedro Francke. "La Desigualdad y la Exclusión han aumentado“. Catedrático de Economía de la Pontificia Universidad Católica del Perú. Diario“La Primera“. 26.07.10. Lima. Perú.

23. Felipe Morris, Pablo Secada y Javier. "Análisis y Propuestas de Reforma del Merado de Capitales en el Perú". (Noviembre 2007).
24. Friedrich, Carl J. 1955. "The Political Thought of Neo-Liberalism”. American Political Science Review 49. 509 525.

25. Humberto Campodònico Sànchez. "La Inversión en el Sector Petrolero Peruano en el periodo 1993-2000". www. eclac.org

26. Humberto Campodónico. "TLC Perú-Chile: No Hay Igualdad de Trato". Diario “La República” 11.03.09. Lima. Perú.

27. Informe sobre "Inversión Extranjera: Comparación del Marco Jurídico en América Latina“. Páginas 13-14

28. Instituto Peruano de Economía. "El Mercado de Capitales Peruanos: Propuesta para Desarrollarlo. (2005).

29. Jacqueline Díaz Munaylla. La Inversión Extranjera en el Perú. www.monografias.com/trabajos7/expe/expe.shtml.

30. Ley de Promoción de la Inversión Privada de las Empresas del Estado. Decreto Legislativo publicado el 27 de Septiembre de 1991. Modificado por Decreto Ley No 25570 publicado el 23 de junio de 1992, Decreto Ley No 26120 publicado el 30 de diciembre de 1992, Ley No 26438 publicada el 11 de enero de 1995 y Decreto Legislativo No 844 publicado el 13 de septiembre de 1996.

31. Luján Juan Maraschio. "Brasil limita información de saneamiento básico. http://news.suite101.net/article.cfm/ brasil-limita-informacion-de-saneamiento-bsico-a12699\#ixzz0vNh7alAl

32. Michael Porter. "Inversión Extranjera en el Perú no Viene a Construir Fábricas". (30/11/2009). Diario "Gestión". Lima. Perú.

33. Nicolás Gadano. "Determinantes de la Inversión en el Sector Petróleo y Gas de la Argentina“. Octubre 1998. 
34. Petroleum Intelligence Weekly (01). «Ranks World's Top 50 Oil Companies (2009)» (en inglés). Consultado el 08/10 del 2010.

35. Plan Nacional 2006 y Sunass.

36. Portafolio. Economía. . "China viene a Colombia por más que los seis aeropuertos que recibirá en concesión“". Marzo 11.2008.

37. Roberto Álvarez. Josè Miguel Benavente. Carmen Contreras. Josè Luìs Contreras. "Consorcios Tecnològicos en Amèrica Latina:Una primera exploraciòn de los casos de Argentina, Chile, Colombia, Uruguay“. Banco Interamericano de Desarrollo. Enero 2010. Página No. 16-17-19-20.

38. Sara Gonzáles y Juan Mascareñas. "La Globalización de los Mercados Finan-
cieros".Universidad Complutense de Madrid. Noticias de la Unión Europea No. 172. Año 1999. Páginas 15-35.

39. Tribunal Constitucional. Gobierno del Perú. Año 1993.

40. Vicerrectorado de Investigaciones. UNMSM. "La Investigación en San Marcos: Balance y perspectivas“. B oletINV No. 16. Julio 2010. Página 3. Lima. Perú.

41. http://alexandervergara.wordpress. com Chile VS. Alemania en Investigación y Desarrollo (I + D).

42. http://americaeconomia.com "Aeropuertos Argentina 2000 aprueba venta de bonos por US\$ 300 M“. 17.09.2010.

43. http://americaeconomia.com "Aeropuertos Argentina 2000 aprueba venta de bonos por US\$300 M“. 17.09.2010. 